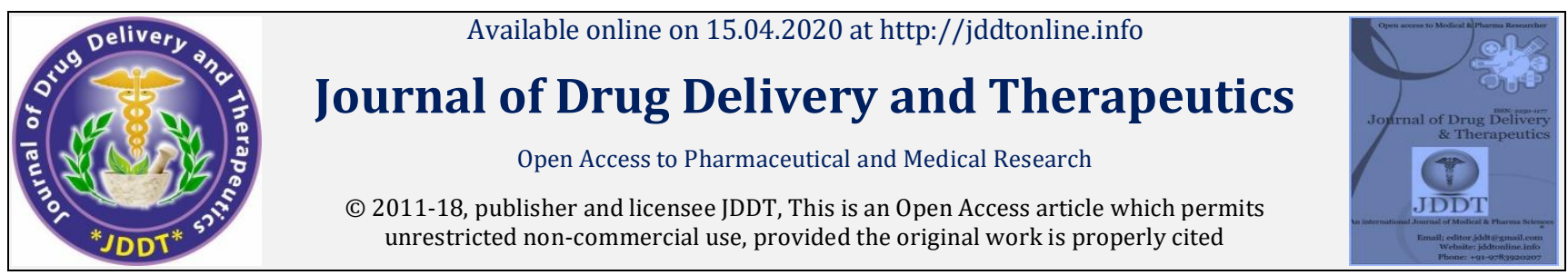

Open $\odot$ Access

Research Article

\title{
Design of Some Benzimidazoles as Target for $\alpha$-Glucosidase Inhibitors
}

\author{
Shweta Mishra*, Rashmi Dahima, Rajesh Sharma \\ School of Pharmacy, Devi Ahilya Vishwavidyalaya, Takshashila Campus, Khandwa Road, Indore-452001, M.P., India
}

\begin{abstract}
Diabetes mellitus is rising globally touching more than 180 million people worldwide. This is prevailing mostly in type 2 diabetes and according to WHO report the incidence is likely to be more than doubled by 2030. $\alpha$-Glucosidase inhibitors work by reducing the amount of glucose that the intestines absorb from food. In this work, forty-five benzimidazole analogues were studied using 3D QSAR, HQSAR, pharmacophore mapping and based on their results 60 compounds were designed. The results show that the best Comparative Molecular Field Analysis (CoMFA) model has $\mathrm{q}^{2}=0.742$ and $\mathrm{r}^{2}=0.973$, and the best Comparative Molecular Similarity Indices Analysis (CoMSIA) model has $\mathrm{q}^{2}=0.679$ and $r^{2}=0.918$. For HQSAR the best model has $\mathrm{q}^{2}=0.773$ and $\mathrm{r}^{2}=0.964$. The $\mathrm{r}^{2}$ value for boostrap for CoMFA and CoMSIA are 0.98 and 0.97 respectively. Pharmacophore mapping revealed varied bioactive regions of ligand. Thus, these compounds could be used as lead for designing the synthesis of potent alpha-glucosidase inhibitors.
\end{abstract}

Keywords: Acarbose, Alpha-glucosidase inhibition, Benzimidazoles, Molecular modelling, Post-prandial hyperglycemia

Article Info: Received 28 Jan 2020; Review Completed 21 March 2020; Accepted 30 March 2020; Available online 15 April 2020

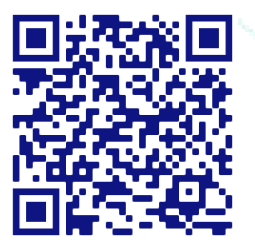

\section{Cite this article as:}

Mishra S, Dahima R, Sharma R, Design of Some Benzimidazoles as Target for $\alpha$-Glucosidase Inhibitors, Journal of Drug Delivery and Therapeutics. 2020; 10(2-s):198-208 http://dx.doi.org/10.22270/jddt.v10i2-s.4017

*Address for Correspondence:

Shweta Mishra, Doctoral Research Fellow, School of Pharmacy, Devi Ahilya Vishwavidyalaya, Takshashila Campus, Khandwa Road, Indore-452001, M.P., India.

\section{INTRODUCTION}

Diabetes mellitus is a persistent metabolic disorder diagnosed by hyperglycemia, glycosuria, hyperlipidemia, negative nitrogen balance and sometimes ketonaemia. Over 18 years of age the international occurrence of diabetes among adults has ascended from $4.7 \%$ in 1980 to $8.5 \%$ in 2014 (Global report on diabetes. WHO, Geneva, 2016). In 2030 diabetes would be the seventh leading cause of death as per the World Health Organization (WHO) (Mathers CD, Loncar D, 2006). The effects of diabetes mellitus include long term damage, dysfunction and of various organs. Adult-onset blindness, lower limb amputations and kidney failure are the major outcomes of diabetes (Alberti K, Zimmet Z.1999).

A common and severe difficulty confronted by many people with type 2 diabetes is postprandial hyperglycemia, $\alpha$ glucosidase inhibitors (AGIs) are well suited for its treatment (Vats Rajesh.2005). Furthermore, $\alpha$-glucosidase may also be used as therapeutic target for other carbohydrate mediated diseases including cancer, HIV and hepatitis. Alphaglucosidase is located in the brush border of the small intestine that acts upon 1, 4- alpha bonds. Most of the carbohydrates are present as oligo- or poly- saccharides, and have to be broken down to disaccharides, before sucrose, isomaltase, maltase, glycol-amylase, and lactase break them into digestible mono-saccharides (Kalra S., 2014). AGIs inhibits both alpha amylase and the other $\alpha$-glucosidases, thus preventing absorption of starch and other carbohydrates from the brush border of the intestine.

Benzo-hydrazides had been reported to possess various biological activities, which includes anti-leishmanial (Taha et al., 2014b), anti-oxidant (Aziz et al., 2014, Khan et al., 2012), anti-glycation (Khan et al., 2013a, Khan et al., 2013b, Khan et al., 2015, Jamil et al., 2015), antibacterial (Imran et al., 2014), and $\alpha$-glucosidase inhibition (Taha et al., 2015f) activities. Benz-imidazole nucleus is an important pharmacophore with unique chemical and biological properties. Benzimidazoles have been found to possess anti-inflammatory (Kohno T, et. al. 1990), antidiabetic (Bhise UN, et. al. 2008), antispasmodic (Francisco $\mathrm{AC}$, et. al. 2006), diuretics (Pashinski VG, et. al. 1978), analgesic (Kohno T, et. al. 1990), antimicrobial (Durmaz R, et. al. 2003), anti-helminthic (Solominova PS, et. al. 2004), antiHIV (Gardiner JM, et. al. 1995), antiulcer (Bariwal JB, 2008), anticancer (Gellis A, et. al. 2008), and anticonvulsant activities (Chimrri A, et al. 2001).

Furthermore, recent studies have shown that some benzimidazole derivatives have been identified to exhibit $\alpha$ glucosidase inhibitory activity. In our work, we have combined benzohydrazide and benz-imidazole nucleus, and developed SAR based on 3D-QSAR, HQSAR studies and 
Pharmacophore Mapping. Further from docking results, 11 compounds were synthesized based on their dock scores. The synthesized compounds were tested for their in vitro $\alpha$ glucosidase inhibitory activity.

\section{MATERIALS AND METHOD}

\section{Molecular modelling}

The molecular modeling studies (CoMFA, CoMSIA, HQSAR, and Pharmacophore mapping) were performed by means of the SYBYL-X 2.1.1 package (Tripos Inc., St. Louis, USA).

\section{Data set}

The biological data sets of 43 benzimidazole derivatives [(26 compounds from the paper of Zawawi et al. (2016) and 19 compounds from Taha et al. (2015) with $\alpha$-glucosidase inhibitory activity were listed in Table 1 . Structural variations of the parent structure, present in all molecules, were allowed at $\mathrm{R}$ position. Using the ligand preparation all the 2D structure of the compounds were standardized to generate a 3D conformation of compounds. They were minimized using Tripos force field (Matthew Clark, et al. 2004) and Gasteiger-Huckel charge with termination gradient of $0.05 \mathrm{kcal} / \mathrm{mol}$, maximum iteration of 1000 , NB cutoff of 8.00 and distance-dependent dielectric constant of 1.00. The $\mathrm{IC}_{50}$ values were converted to the corresponding $\mathrm{pIC}_{50}\left(-\log \mathrm{IC}_{50}\right)$ and used as dependent variables in the QSAR analysis.

\section{Alignment}

One of the fundamental assumptions wherein 3D-QSAR studies are based is that a geometric similarity should exist between the structures to obtain valid and reliable models. A proper molecular alignment adjusts the geometry of the molecules such that its steric and electrostatic fields match the fields of the template molecule which is the most essential for the quality and the predictive ability of CoMFA and CoMSIA models. In the present study by using the align database function in Sybyl 2.1.1 the most active compound 19 is used as a template (red color) for superimposition, which is assumed to represent the most bioactive conformation among the given set. All the molecules were aligned by the Align Database command available in Sybyl using maximum substructure. Figure 1 shows the stereo view of all the aligned molecules (Agarwal A, et al. 1993, Baurin N, et al. 2000)

\section{Molecular Modelling}

The forty-three benzimidazole analogues exhibited significant $\alpha$-glucosidase inhibitory activity (Table 1 ). In the series parent derivative 19 was chosen as template which have electron-donating groups at 3, 4, and 5 positions.

\section{RESULT AND DISCUSSION}

The structures of compounds used in training and test set shown in Table 1 . Using the series of benzimidazole and benzimidazole benzhydrazide derivatives possessing $\alpha$ glucosidase inhibitory activity, 3D-QSAR models were derived. The CoMFA and CoMSIA models (Table 2 and 3) were developed using common substructure-based based alignment scheme.

The grey color shows the carbon atom, cyan color shows the hydrogen atoms, blue color shows the nitrogen atoms and red color shows oxygen atom.

During the molecular modeling process, 14 compounds out of the total $45 \alpha$-glucosidase inhibitors were selected as the testing set for model validation $(1,10,14,17,20,22,24,27$,
$28,33,34,35$ and 38) and remaining in training set were selected by diversity method.

Several statistical parameters including $\mathrm{R}_{\mathrm{cv}}{ }^{2}, \mathrm{R}_{\mathrm{ncv}}{ }^{2}$, SEE and $\mathrm{F}$ values should be evaluated to judge whether a QSAR model is reliable for prediction of unknown molecules. The statistical results of the optimum models are summarized in Table 4.

A high $\mathrm{R}_{\mathrm{cv}}{ }^{2}$ of 0.742 with five components was yielded by the statistical CoMFA model which provide an accurate internal predictive capacity of the model. Self-consistency was proven by a high $R_{n c v}{ }^{2}$ of 0.973 with a low standard error estimate (SEE) of 0.08 for the final model. In case of the relative contributions, steric (S) and electrostatic (E) accounted for $42.4 \%$ and $57.6 \%$ respectively, signified that the E field delivered more to the binding affinities.

Actual $\mathrm{pIC}_{50}$ versus predicted $\mathrm{pIC}_{50}$ values for the training and test sets using CoMFA model is depicted in the scatter plot figure 2a. In CoMSIA, SEHD model displays good internal predictions relative to the CoMFA model, which ends in statistical results of $\mathrm{R}_{\mathrm{cv}}^{2} 0.70, \mathrm{R}_{\mathrm{ncv}}^{2} 0.938, \mathrm{~F}=69.84$ with four optimal components. Using CoMSIA model the actual pIC50 versus predicted $\mathrm{pIC}_{50}$ values for the training and test sets the scatter plot is displayed in figure $2 \mathrm{~b}$. Clearly, all points are uniformly distributed around the regression line, suggesting the reliable predictive ability of the model. To validate the efficacy of the obtained models (CoMFA and CoMSIA) the test set molecules are further used.

\section{3-D QSAR Contour maps}

To view the field effects on the target features the stdev*coeff contour maps were constructed. The contour maps of CoMFA (steric and electrostatic), and CoMSIA (steric, electrostatic, and hydrophobic, donor) were shown in figure 3 and figure 4, respectively. For visualization compound 19 was labelled and displayed in the map. The area in the space where the aligned molecules would favorably or unfavorably interact with the enzyme is denoted by the CoMFA contour while those regions within the particular area where the presence of a group with a specific physicochemical property will be favored or disfavored for biological activity.

Compound 19 was served as reference molecule. In the CoMFA steric field as shown in figure 4a, a large green contour polyhedron located around the $\mathrm{R}$ suggested that bulky groups had benefited well for the activity. This finding is clarified by the example that $-\mathrm{OH}$ substituent $(4,5,6,7,9$, 10 and 12) in $\mathrm{R}$ region exhibited potent $\alpha$-glucosidase inhibitory activity than molecules with and without $-\mathrm{OH}$ substituent at particular o-position, and p-position. Two yellow color contours indicated that bulky groups were steric unfavorable near benzimidazole nitrogen atom as steric clash might occur. Another small green contour on the 4,5-dimethylene group was consistent which would enhance the activity.

The electrostatic field contour was demonstrated in figure. 3b. A large blue polyhedral is observed outside the $R$ substituent and around a small red isopleth at the $R$ substituent which strongly restricts the sideward relocatability, also shows that electropositive substituents stretched to this contour would benefit for the inhibitory activity. Hydroxyl groups when present at o-position (compound 6) or one hydroxyl group and one methoxy group was present at o-position/p-position (compound 4, 10, 12), bearing negative charge, increases the activity; while methyl at 2', 3' and 4' position (compound 13, 14, 16) having positive charge decreases the activity. Electron donating substituents (compound 4, 5, 6, and 19) at R gives better 
activity than electron withdrawing groups (compound 8, 22, 25 , and 26).

In figure 4a the steric contour map of CoMSIA is displayed. Steric contour maps of CoMFA can be well compared with two green and two yellow contours of CoMSIA steric map. Likewise, the electrostatic contour map of CoMSIA is very similar to that of CoMFA map (Figure $4 \mathrm{~b}$ ). As the CoMSIA contour maps are very similar to those of CoMFA, merely hydrophobic contour map is discussed here. Yellow color at the R substituent and 4,5-dimethylene group shows bulky or hydrophobic substituents will favor the activity, while white contour near the hydrazide moiety and linker benzene ring shows disfavored areas for inhibitory activity (Figure 4c). A small white contour behind the yellow contour, indicates that size of the hydrophobic substituent may affect the inhibitory potency. It will show hydrophobic clashes with this region if any substituent extends to yellow polyhedral. The steric contour of CoMFA may perfectly coincide with results of hydrophobic contour. Purple color at the $\mathrm{NH}$ of imidazole and $\mathrm{O}$ of the linker, indicates that the bulky donor group is not desirable at these positions whereas the cyan color on the $\mathrm{NH}$ and benzene ring of the linker favors the substitution of a donor group. (Figure 4d)

The best statistical parameter was obtained from the combination of atom, bond and donor atom $\left(\mathrm{q}^{2}=0.773, \mathrm{r}^{2}=\right.$ $0.964, \mathrm{R}_{\mathrm{se}}{ }^{2}=0.103, \mathrm{q}_{\mathrm{se}}{ }^{2}=0.255$ ) based on the hologram length 97 and 6 components. The HQSAR statistical model generated using default fragment size (4-7) with fragment distinct (A/B/DA) gave a cross-validated correlation coefficient $\left(\mathrm{q}^{2}\right)$ of 0.773 , non-cross-validated correlation coefficient $\left(\mathrm{r}^{2}\right)$ of 0.964 , low standard error estimate (SEE) of 0.103 with an optimized component of 6 , and Pred $r^{2}$ of 0.732 was obtained. Thus, the HQSAR model obtained here was reliable. The scatter plot for the actual $\mathrm{pIC}_{50}$ versus predicted $\mathrm{pIC}_{50}$ values for the training and test sets is displayed in figure 2 (c). On the basis of different colors HQSAR graphically delivers evidence on the atomic or fragment contributions to the activities. The colours at the green end (yellow, green-blue and green) reflect positive contribution, colours at the red end of the spectrum (red, red-orange and orange) reflect negative contribution and neutral contributions are coloured in white. The most active molecular fragments of compound 19, most potent $\alpha$ glucosidase compound of the data set are shown in figure 5 . According to the contribution maps, the molecular fragments corresponding to the unsaturated ring are strongly related to biological affinity at C1, C2 and C6 (coloured in green and yellow).

DISCO proposed Model 443 (Figure 6), a eleven point model (AL 02, DL 01, HY 03, AR 02, AS 02) with a tolerance of $1 \AA$. Hydrogen bond donor atoms (DL) and hydrogen bond acceptor atoms (AL) is the nitrogen of imidazole function, and (HY) is the center of the benzimidazole ring and linker benzene ring attached to hydrazide moiety. The nitrogen function of the inhibitor molecules is believed to mimic the ring oxygen group present in oligosaccharide and is confirmed as the primary site of binding. The enzymatic reaction would stop because the $\mathrm{C}-\mathrm{N}$ linkage in the designed inhibitor molecule can't be cleaved. As long as inhibitor bound to the alpha-glucosidase enzyme, ingested carbohydrates cannot be digested and glucose cannot be released for absorption. So, the benzimidazole moiety is important for the activity no changes should be made in that region. Results of pharmacophore hypothesis generated by DISCOtech are shown in Table 6. Model 443 was considered as the best model as it had highest score of 4.4232 compared to remaining five hundred models. The pharmacophoric feature points and the interatomic distances between groups are presented in figure 6 .

After the DISCOtech, Genetic Algorithm with Linear Assignment of Hypermolecular Alignment of Database (GALAHAD) was runned, ten pharmacophore models were generated with population size set to 80-100 and other default parameters, for which statistical values are listed in Table 6. Therefore, Model_443 was considered to be the best model and its statistical values are listed in Table 9. As shown in Figure 7, this model contains three acceptor atoms, three donor atoms and three hydrophobes, and the nitrogen atoms of benzimidazole group acts both acceptor and donor atoms.

The important key finding obtained from CoMFA, CoMSIA, HQSAR analysis and Pharmacophore mapping promotes us to suggest some novel $\alpha$-glucosidase antagonist compounds. The molecular modelling analysis provided adequate information regarding the structural requirements for enhanced $\alpha$-glucosidase inhibitory activity.

The CoMFA, CoMSIA and HQSAR contours contribution maps guide us to optimize the accessible scaffold. Based on the molecular modelling recommendation without disturbing the pharmacophore bulky, electron donating, hydrophobic at the R position enhance activity; electron donating, electronwithdrawing and hydrophobic substituent are favored at linker between the hydrazide and benzimidazole; and minor, fewer bulky substituents at benzimidazole assistance potency through CoMFA and CoMSIA. Moreover, HQSAR advice that saturated and linked aromatic side chain showed positive contribution. The group imidazole, hydrazide, $\mathrm{NH}[\mathrm{C}=\mathrm{O}] \mathrm{CH} 3$, and $-\mathrm{OH}$ were essential for binding to the inhibitors site cavity (protomol). The structure activity relationship explored by this study is presented in figure 7 .

\section{CONCLUSION}

In this study, 3D QSAR, HQSAR and Pharmacophore mapping analysis is described as a rational strategy for the design of novel alpha glucosidase inhibitors. All the models (CoMFA, CoMSIA and HQSAR) were found satisfactory according to the statistical parameters. CoMFA and CoMSIA models are found to be good according to the statistical results as well as the contour maps analysis. It can further be concluded from the results that the compounds may be due to bulky substitution of benzimidazole ring and existence of electron donating group on $\mathrm{R}$. Based on the molecular modeling results the designed compounds can further be synthesized and biological evaluation can be done for alpha-glucosidase activity.

\section{REFERENCES}

1. Global report on diabetes. WHO, Geneva, 2016.

2. Mathers CD, Loncar D. Projections of global mortality and burden of diseases from 2002 to 2030. Plos Med, 2006; 3 (11):442.

3. Alberti K, Zimmet Z. Definition, diagnosis and classification of diabetes mellitus and its complications: Report of a WHO Consultation. 1999; 1:125.

4. Kalra S. Alpha glucosidase inhibitors. J. Pak Med. Assoc. 2014; 64(4):474-476.

5. Hanefeld M, Schaper F. The role of Alpha-Glucosidase Inhibitors (Acarbose). Pharmacotherapy of Diabetes: New Developments. Diabetes: Endocrinology. US Springer, 2007; 143-52.

6. Aziz AN, Taha M, Ismail NH, Anouar EH, Yousuf S, Jamil W, Awang K, Ahmat N, Khan KM, Kashif Synthesis SM, crystal structure, DFT studies and evaluation of the antioxidant activity of 3,4dimethoxybenzenamine schiff bases, Molecules, 2014; 19:84148433 
7. Imran S, Taha M, Ismail NH, Khan KM, Naz F, Hussain M, Tauseef S, Synthesis of novel bisindolylmethane schiff bases and their antibacterial activity Molecules, 2014; 19:11722-11740

8. Jamil W, Perveen S, Shah SSA, Taha M, Ismail NH, Perveen S, Ambreen N, Khan KM, Choudhary MI, Phenoxyacetohydrazide schiff bases: $\beta$-glucuronidase inhibitors, Molecules, 2014; 19:8788-8802

9. Jamil, W., Solangi, S., Ali, M., Khan, K.M., Taha, M., Khuhawar, M.Y., 2015 Syntheses, Characterization, In Vitro Antiglycation and DPPH Radical Scavenging Activities of Isatin Salicylhydrazidehydrazone and its Mn (II), Co (II), Ni (II), Cu (II), and Zn (II) Metal Complexes. Arabian J. Chem. (http://dx.doi.org/10.1016/j.arabjc.2015.02.015) (in press).

10. Khan KM, Taha M, Naz F, Siddiqui S, Ali S, Rahim F, Perveen S, M.I. ChoudharyAcylhydrazide Schiff bases: DPPH radical and superoxide anion scavengers, Med. Chem., 2012; 8:705-710

11. Khan KM, Taha M, Rahim F, Fakhri MI, S. Rasheed S, Rahim F, Jamil W, M. Khan, Karim A, Perveen S, choudhary MI, Acylhydrazide schiff bases: synthesis and antiglycation activity, J. Chem. Soc. Pak., 2013; 35:930-938

12.Khan KM, Rahim F, Ambreen N, Taha M, Khan M, Jahan H, Shaikh NA, S. Iqbal, Perveen S, Choudhary MI, Synthesis of benzophenonehydrazone Schiff bases and their in vitro antiglycating activities, Med. Chem., 2013; 9:588-595

13. Khan KM, Irfan M, M. Ashraf, Taha M, Saad SM, Perveen S, Choudhary MI, Synthesis of phenyl thiazole hydrazones and their activity against glycation of proteins, Med. Chem. Res., 2015; 24:3077-3085

14. Taha M, Ismail NH, Ali M, K.M. Khan, W. Jamil, S.M. Kashif, M. Asraf, Synthesis of indole2-hydrazones in search of potential leishmanicidal agents, Med. Chem. Res., 2014; 23:5282-5293

15.M. Taha, N.H. Ismail, A. Khan, A.A.S. Syed, A. Anwar, S.A. Halim, M. Q. Fatmi, S. Imran, F. Rahim, K.M. Khan, Synthesis of novel derivatives of oxindole, their urease inhibition and molecular docking studies, Bioorg. Med. Chem. Lett., 2015; 25:3285-3289

16. Taha M, Ismail NH, Baharudin MS, Lalani S, Mehboob S, Khan KM, S. yousuf, S. Siddiqui, F. Rahim, M.I. Choudhary, Synthesis crystal structure of 2-methoxybenzoylhydrazones and evaluation of their a-glucosidase and urease inhibition potential, Med. Chem. Res., 2015; 24:1310-1324

17. Taha M, Ismail NH, Imran S, Rokei MQB, Saad SM, Khan KM, Synthesis of new oxadiazole derivatives as $\alpha$-glucosidase inhibitors, Bioorg. Med. Chem., 2015; 23:4155-4162

18. Kohno T, Ohtaka H, Tsukamoto G, Yoshino K: Synthesis and antiinflammatory activity of some 2- (substituted-pyridinyl) benzimidazoles. Journal of Medicinal Chemistry 1980, 23:734738.

19. Bhise UN, Kumar SBV, Ramanatham V, Vaidya SD: Synthesis, antibacterial, anti-asthmatic and antidiabetic activities of novel $\mathrm{N}$-substituted benzimidazoles. European Journal of Medicinal Chemistry 2008, 43(5):986-995.
20. Francisco AC, Gabriel NV, Hermenegilda MD: Design, microwaveassisted synthesis and spasmolytic activity of 2-(alkyloxyaryl)1H-benzimidazole derivatives as constrained stilbene bioisosteres. Bioorganic and Medicinal Chemistry Letters 2006, 16(16):4169-4173.

21. Pashinski VG, Romanova TV, Mukhina NA, Shkrabova LV: Diuretic activity of benzimidazole urea derivatives. Farmakol Toksikol 1978, 41(2):196-9.

22. Durmaz R, Gunal S, Kucukbay H: Synthesis, antibacterial and antifungal activities of electron-rich olefins derived benzimidazole compounds. Science Direct: II Farmaco 2003, 58:431-437.

23. Solominova PS, Pilyugin VS, Pyurin AA: Targated search for new anthelmentic among 5 (6- Aminophenylthio (oxy)-2-amino benzimidazole derivatives. Journal of Pharmaceutical Chemistry 2004, 38:425-430.

24. Gardiner JM, Loyns CR, Burke A, Khan A: Synthesis and HIV -1 inhibition of novel benzimidazole derivatives. Bioorganic and Medicinal Chemistry Letters 1995, 5(12):1251-1254.

25. Bariwal JB, Shah AK, Kathiravan MK, Somani RS, Jagtap JR: Synthesis and antiulcer activity of novel pyrimidylthiomethyl and Pyrimidylsulfinylmethyl benzimidazoles as potential reversible proton pump inhibitors. Indian Journal of Pharmaceutical Education and Research 2008, 42(3):225-231.

26. Durmaz R, Gunal S, Kucukbay H: Synthesis, antibacterial and antifungal activities of electron-rich olefins derived benzimidazole compounds. Science Direct: II Farmaco 2003, 58:431-437.

27. Chimrri A, Sarro AD, Sarro GD, Giho G, Zappala M: Synthesis and anticonvulsant properties of 2, 3, 3a-4-tetrahydro-1-H pyrrolo (1,2-a) benzimidazol-1-one derivatives. Science Direct: II Farmaco 2001, 56(11):821-826.

28. Zawawi et al. Benzimidazole derivatives as new $\alpha$-glucosidase inhibitors and in silico studies. Bioorganic Chemistry J. 2016; 64: 29-36.

29. Taha M. Synthesis crystal structure of 2methoxybenzoylhydrazones and evaluation of their $\alpha$ glucosidase and urease inhibition potential. Medicinal chemistry research J. 2015, 24; 3:1310-1324.

30. Taha M. Synthesis of novel derivatives of 4-methylbenzimidazole and evaluation of their biological activities. European Journal of Medicinal Chemistry. 2014; 84:731-738.

31. Matthew Clark, Richard D. Cramer III , Nicole Van Opdenbosch, Validation of the general purpose tripos 5.2 force field, 2004, 10; 8: 982-1012

32. Agarwal A, Taylor EW. 3-D QSAR for intrinsic activity of 5-HT1 A receptor ligands by the method of comparative molecular field analysis. J Comput Chem. 1993; 14(2):237-245.

33. Baurin N, Vangrevelinghe E, Morin-Allory L, Me'rour JY, Renard P, Payard M, Guillaumet G, Marot C. 3D-QSAR CoMFA study on imidazolinergic I2 ligands: a significant model through a combined exploration of structural diversity and methodology. J Med Chem. 2000; 43:1109-1122. 
Table 1: Structures and inhibitory activity values of benzimidazoles derivatives

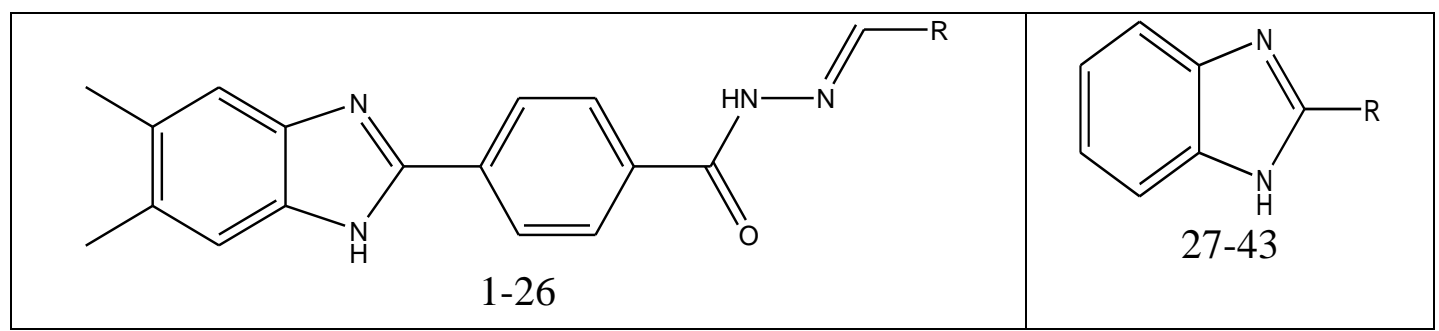

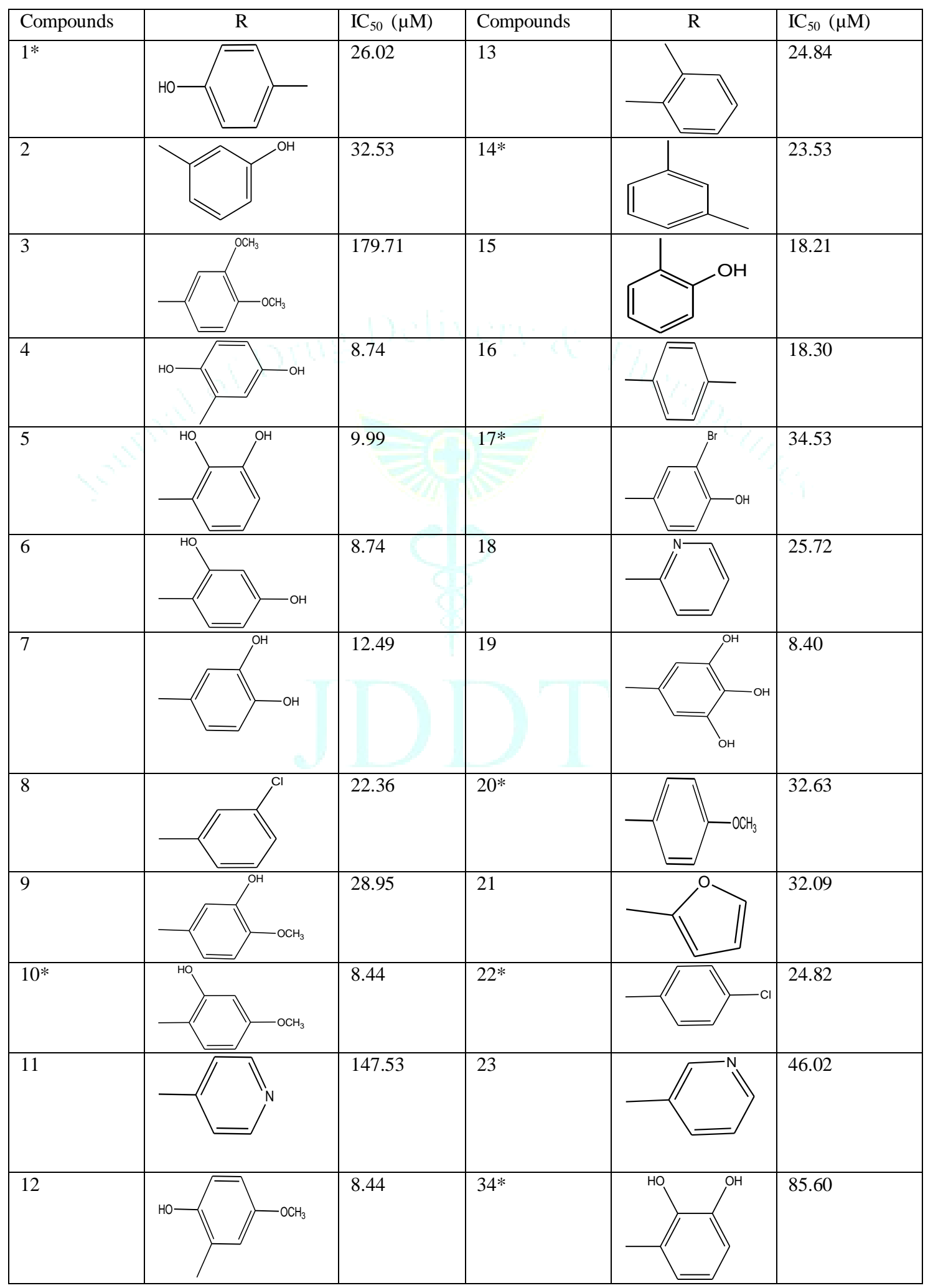




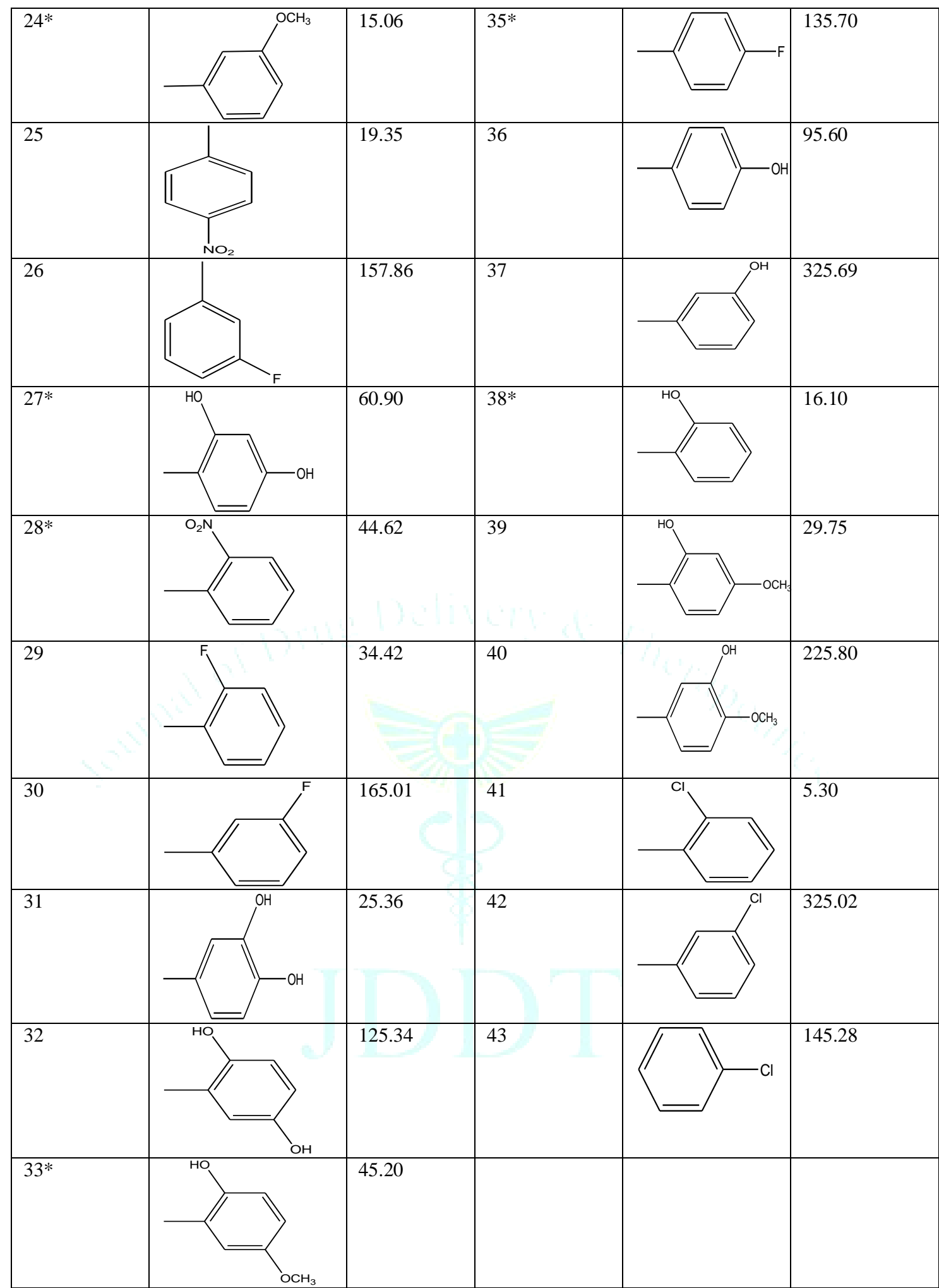

* test set 


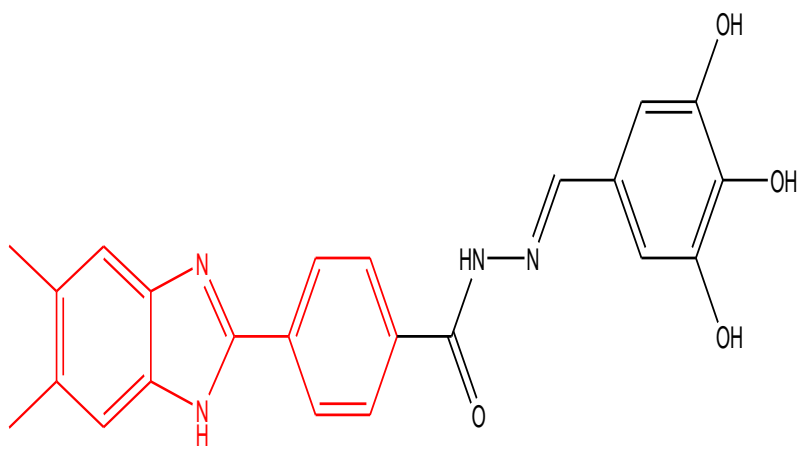

TEMPLATE

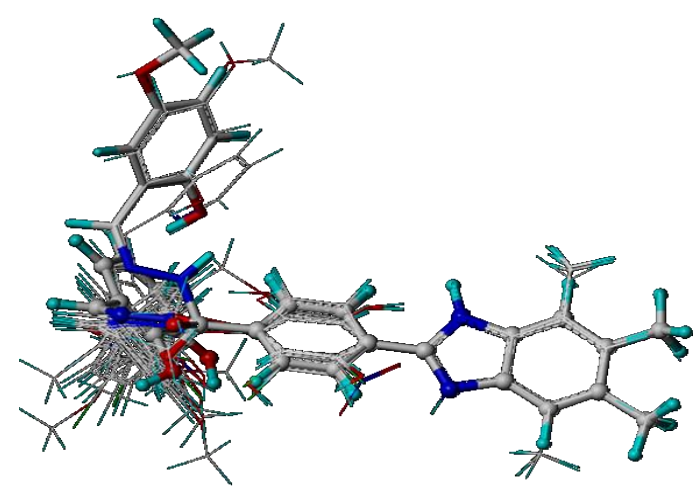

ALIGNMENT

Figure 1: a. Template molecule (19) used for the molecular alignment (core structure for alignment is shown in red) b. Threedimensional data set alignment.

Table: 2 CoMFA model on different charges

\begin{tabular}{|l|l|l|l|l|}
\hline CHARGES & $q^{2}$ & $r^{2}$ & SE & $\begin{array}{l}\text { NO. } \\
\text { COMP. }\end{array} \quad$ OF \\
\hline Gasteiger & 0.706 & 0.913 & 0.150 & 4 \\
\hline Gast Huckel & 0.693 & 0.891 & 0.173 & 4 \\
\hline Pullman & 0.700 & 0.899 & 0.160 & 4 \\
\hline Formal charges & 0.592 & 0.791 & 0.234 & 3 \\
\hline Delre & 0.742 & 0.973 & 0.080 & 5 \\
\hline MMFF94 & 0.701 & 0.889 & 0.174 & 4 \\
\hline \multicolumn{7}{|c|}{ CoMFA on Delre charge } \\
\hline \multicolumn{7}{|c|}{ clogP } & 0.443 & 0.948 & 0.12 & 5 \\
\hline
\end{tabular}

Table: 3 CoMSIA with different combinations on Delre charge

\begin{tabular}{|c|c|c|c|c|}
\hline COMBINATIONS & $q^{2}$ & $r^{2}$ & SE & NO. OF COMP. \\
\hline S & 0.626 & 0.766 & 0.24 & 3 \\
\hline E & 0.634 & 0.883 & 0.175 & 2 \\
\hline H & 0.577 & 0.721 & 0.26 & 4 \\
\hline D & 0.624 & 0.878 & 0.18 & 4 \\
\hline S + E & 0.637 & 0.852 & 0.201 & 3 \\
\hline S + E + H & 0.707 & 0.905 & 0.158 & 4 \\
\hline S + E + H + D & 0.7 & 0.915 & 0.153 & 4 \\
\hline S+ E+H+D+ A & 0.679 & 0.918 & 0.149 & 3 \\
\hline
\end{tabular}

Table: 4 The statistical results of the CoMFA and CoMSIA analyses for the training and test set compounds

\begin{tabular}{|l|l|l|}
\hline & CoMSIA & CoMFA \\
\hline $\mathrm{R}_{\mathrm{ncv}}{ }^{2}$ & 0.938 & 0.973 \\
\hline $\mathrm{R}_{\mathrm{cv}}{ }^{2}$ & 0.70 & 0.742 \\
\hline $\mathrm{F}\left(\mathrm{n}_{1}=5, \mathrm{n}_{2}=23\right)$ & 69.84 & 164.78 \\
\hline $\mathrm{SEE}$ & 0.133 & 0.08 \\
\hline $\mathrm{R}_{\text {pred. }}^{2}$ & 0.729 & 0.732 \\
\hline $\mathrm{R}_{\text {bootstrap }}$ & 0.97 & 0.98 \\
\hline $\mathrm{SD}$ & 0.010 & 0.014 \\
\hline Field contribution & \multicolumn{2}{|l|}{} \\
\hline $\mathrm{S}$ & 0.177 & 0.424 \\
\hline $\mathrm{E}$ & 0.634 & 0.576 \\
\hline $\mathrm{H}$ & 0.189 & - \\
\hline $\mathrm{D}$ & 0.009 & - \\
\hline $\mathrm{A}$ & - & - \\
\hline
\end{tabular}




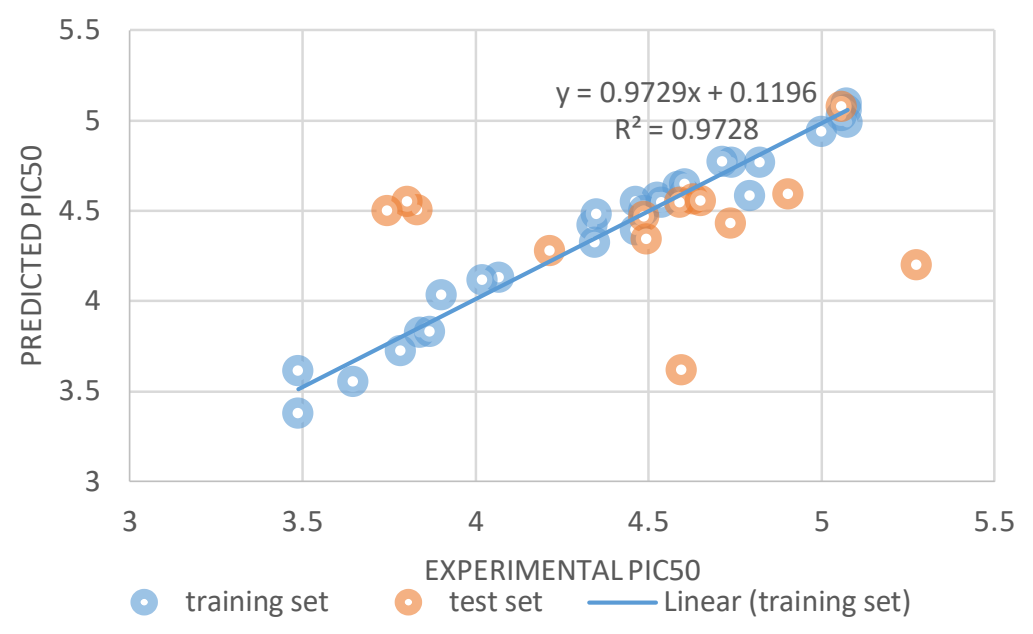

Figure 2a: Graph of actual versus predicted pIC50 values of the training set and the test set molecules of Model 2 (Delre) using the CoMFA model.

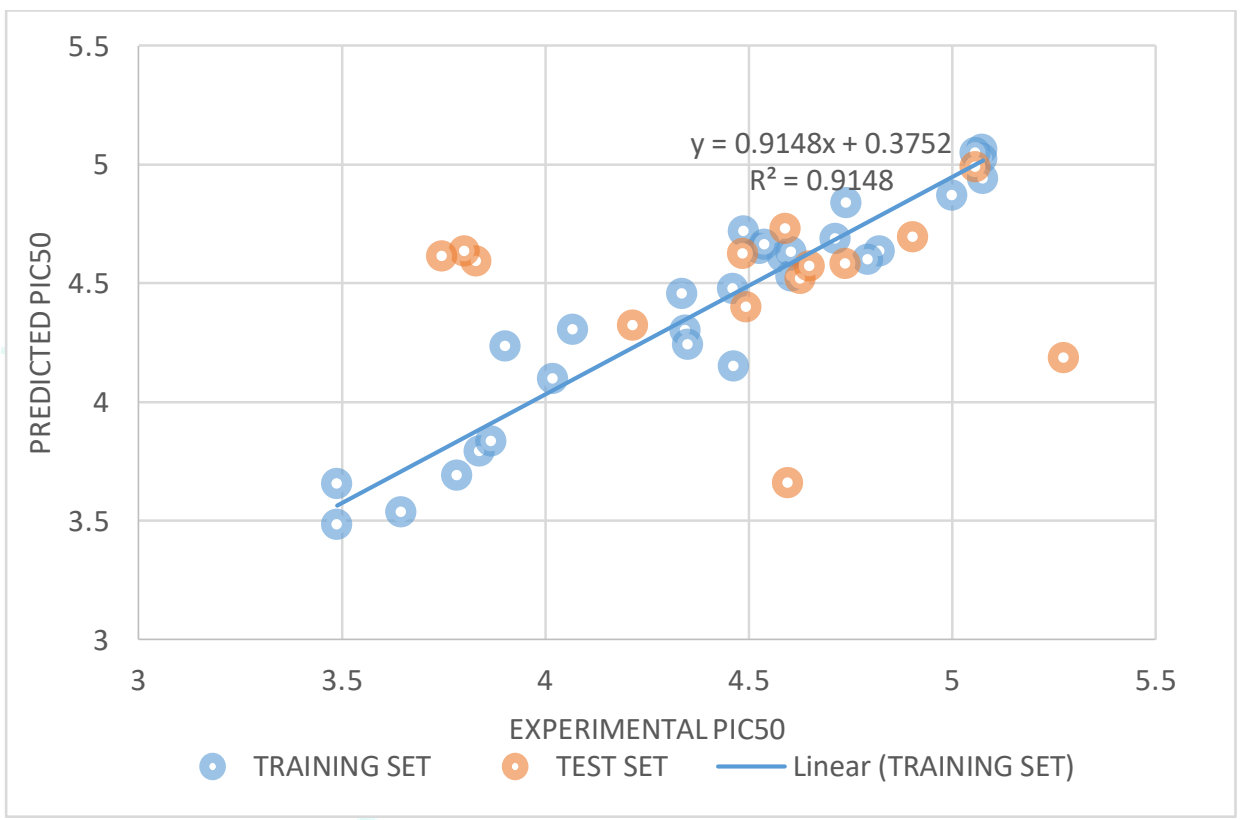

Figure 2b: Graph of actual versus predicted pIC50 values of the training set and the test set molecules of Model 29 (MMFF94) using the CoMSIA model.

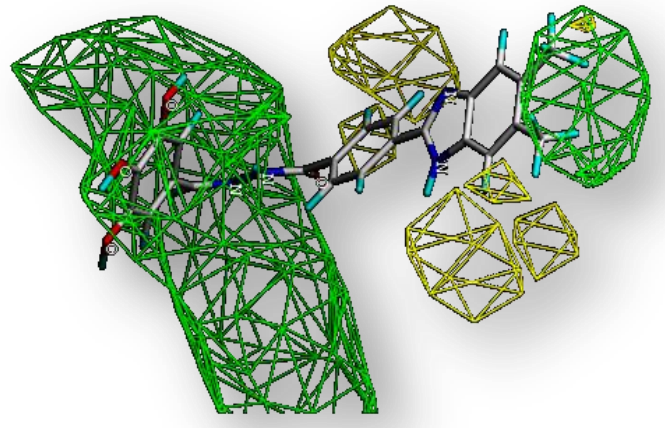

(a) STERIC

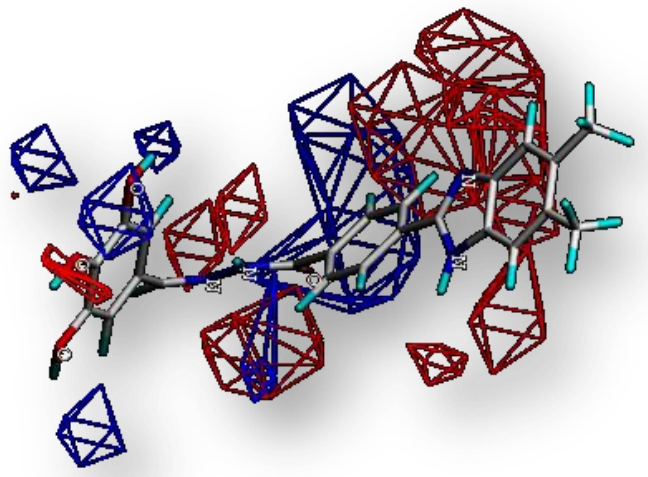

(b) ELECTROSTATIC

Figure 3: Contour maps for CoMFA model. 


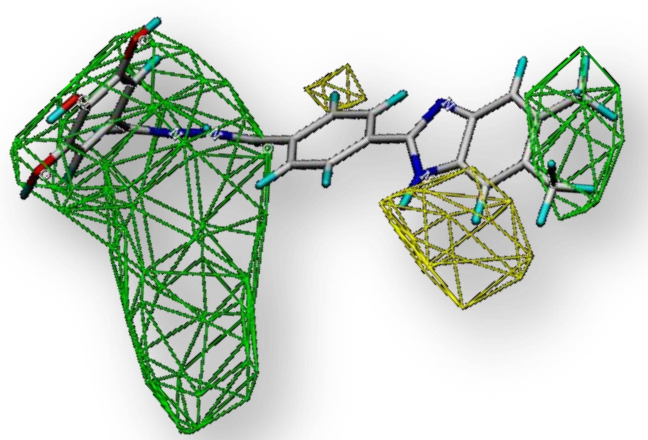

(a) STERIC

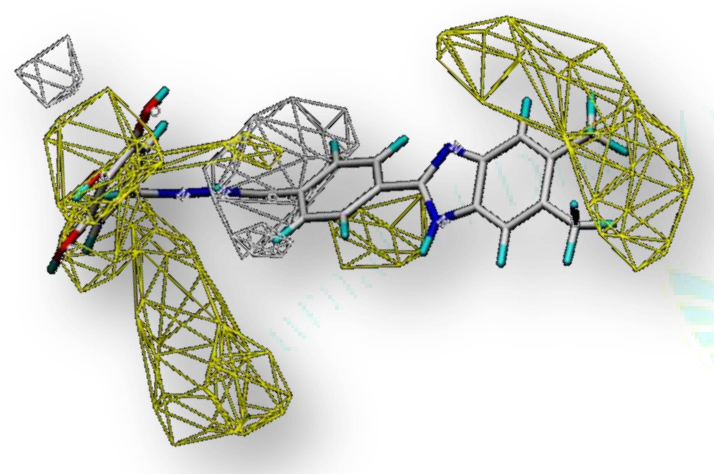

(c) HYDROPHOBIC

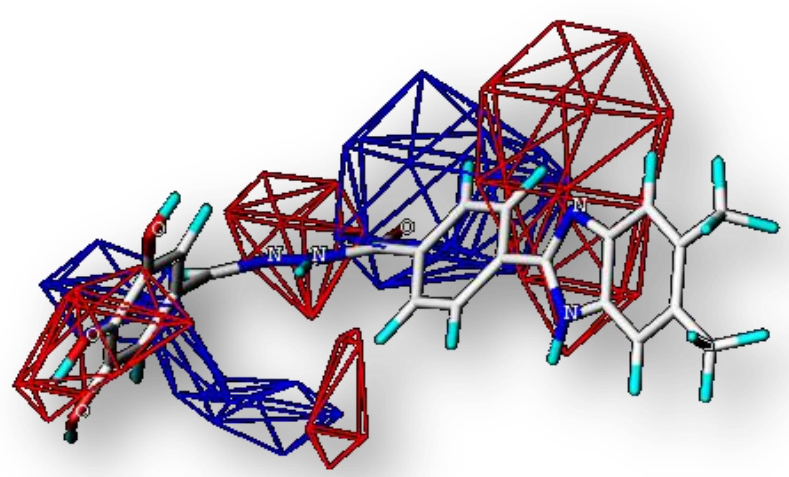

(b) ELECTROSTATIC

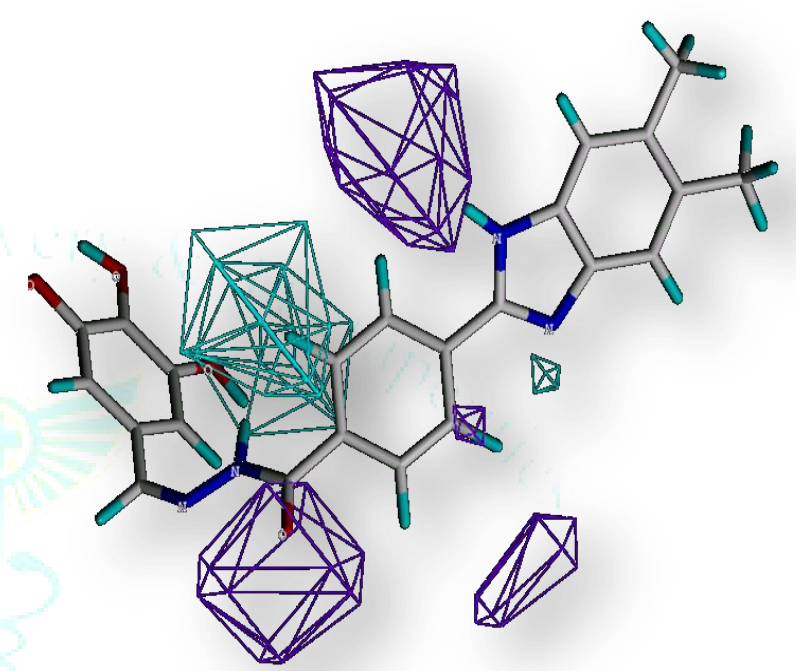

(d) DONOR

Figure 4: Contour maps for CoMSIA model.

Table 5: Summary of the statistical parameters of HQSAR studies:

\begin{tabular}{|c|c|c|}
\hline S.no. & Statistical parameters & model \\
\hline 1. & Fragment size & $6-9$ \\
\hline 2. & $\mathrm{Q}^{2}$ & 0.731 \\
\hline 3. & $\mathrm{R}^{2}$ & 0.974 \\
\hline 4. & Ensemble & 0.968 \\
\hline 5. & $\mathrm{SE}$ & 0.088 \\
\hline 6. & $\mathrm{NC}$ & 6 \\
\hline 7. & Best length & 257 \\
\hline
\end{tabular}




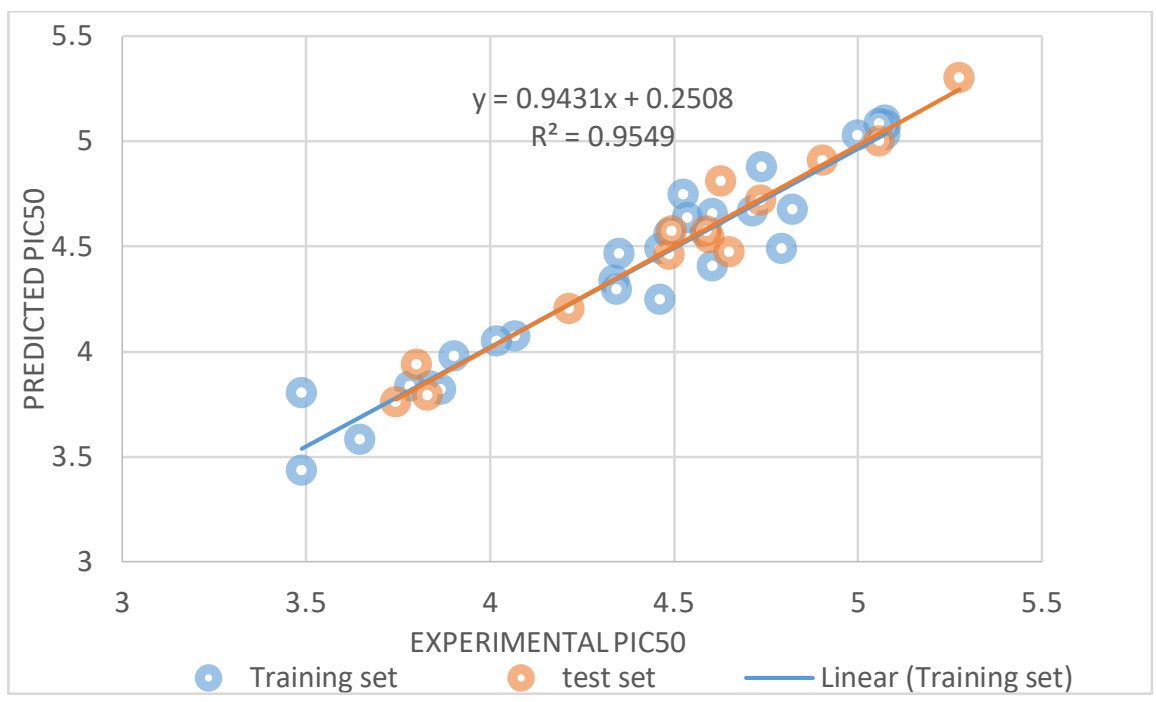

Figure 2c: Graph of actual versus predicted pIC50 values of the training set and the test set molecules of Model A/B/DA at 6-9 fragment size using the HQSAR

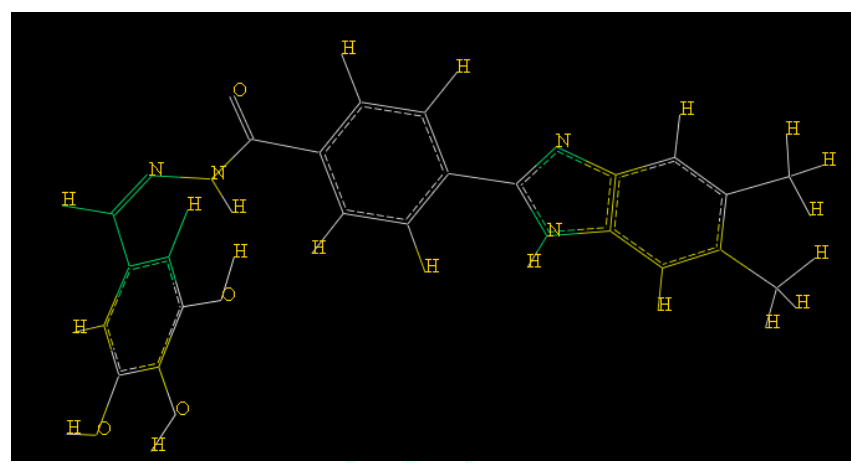

Figure 5: HQSAR contour map for compound 19 (most active)

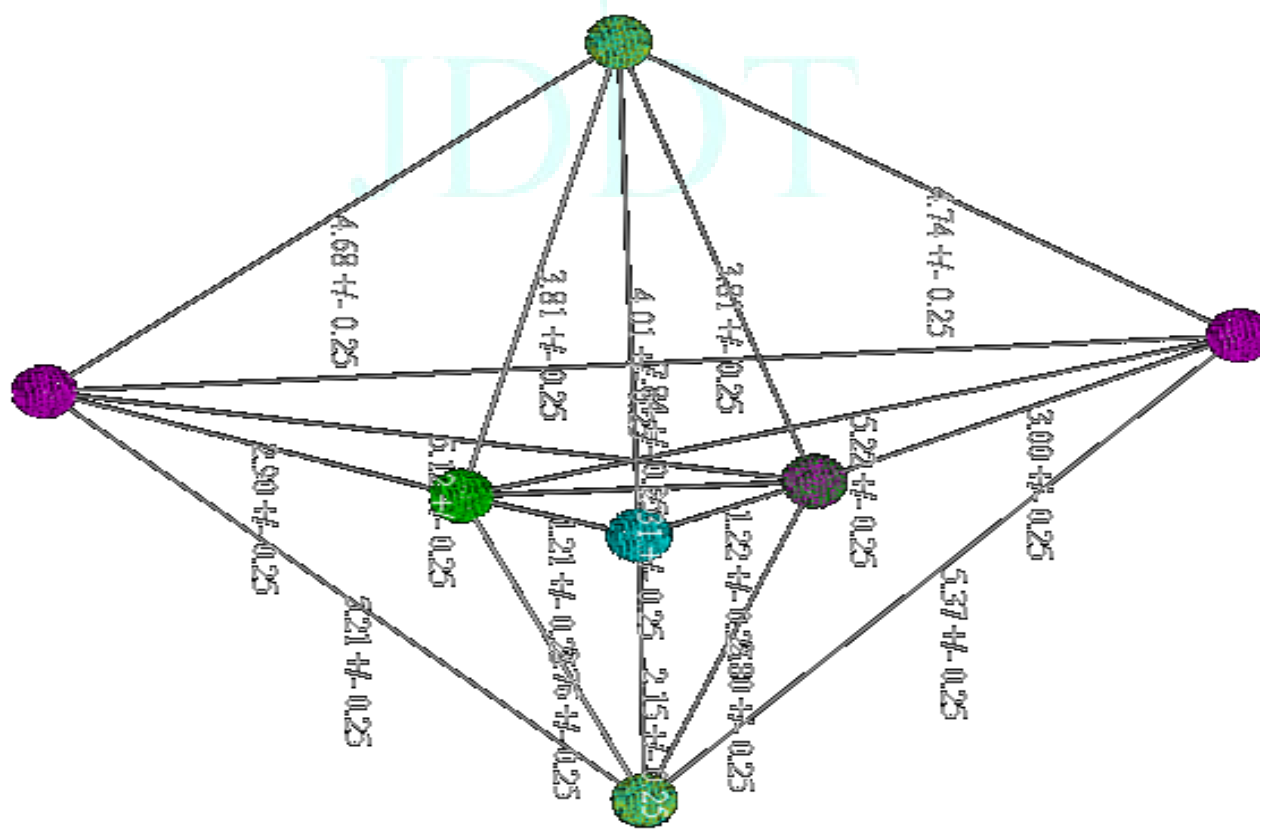

Figure 6: Pharmacophoric feature points and the interatomic distances between groups 
Table 6: Number of models obtained along with the pharmacophoric features and tolerance values of each of the DISCOTech pharmacophoric run

\begin{tabular}{|l|l|l|l|l|l|l|}
\hline Name & Size & Hits & Score & Tolerance & DMEAN & Activities \\
\hline MODEL_443 & 10 & 29 & 4.4232 & 0.25 & 3.6758 & $325 \ldots . .00$ \\
\hline
\end{tabular}

a. SIZE - number of features in the model,

b. HITS - number of molecules that matched during the search,

c. SCORE - an overall measure of fit and of overlap for the entire collection of structures,

d. TOLERANCE - initial tolerance setting,

e. DMEAN - average interpoint distance.

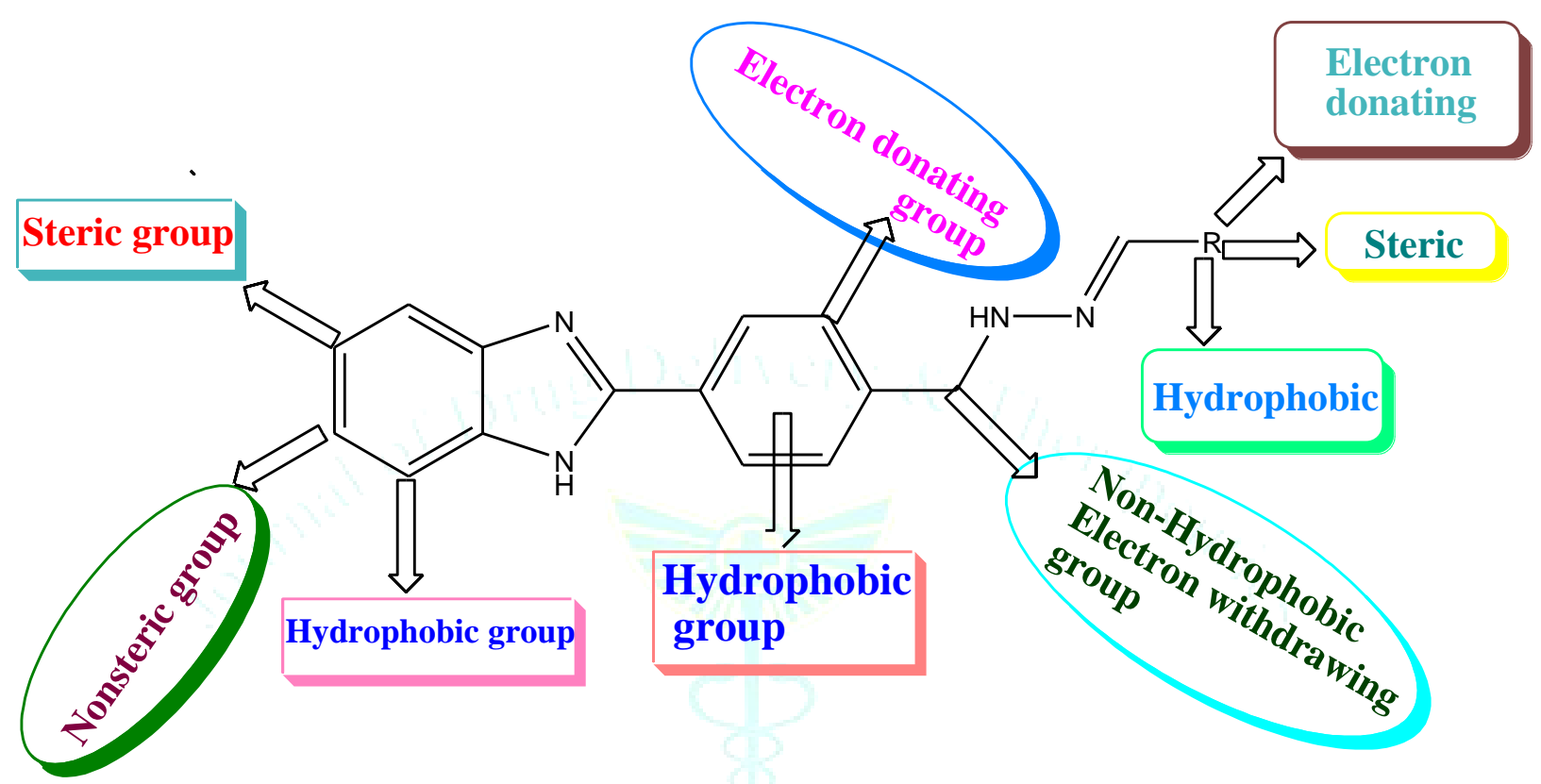

Figure 7: Structure activity relationship developed by the CoMFA, CoMSIA, HQSAR and Pharmacophore mapping 